\title{
Productive and cognitive innovation strategy: African framework design
}

\section{Godwin Chukwudum Nwaobi}

Quantitative Economic Research Bureau, P. O. Box 7173 Aba, Abia State, Nigeria, West Africa

\section{Email address:}

gcnwaobi@quanterb.org

\section{To cite this article:}

Godwin Chukwudum Nwaobi. Productive and Cognitive Innovation Strategy: African Framework Design. International Journal of Business and Economics Research. Vol. 3, No. 2, 2014, pp. 50-65. doi: 10.11648/j.ijber.20140302.12

\begin{abstract}
Since the mid 1990's, economist have come to recognize the role of innovative activity in firms productivity growth, particularly in the competitive market economies. However, the most conducive market environment for innovative activity has also become a subject of interest. Thus, a major constraint on industrial dynamism in African countries is said to be the dearth of indigenous entrepreneurs. This paper therefore argued for the provision of comprehensive innovation policy, in which the government supports the innovators by providing appropriate financial measures, removing regulatory, institutional (competitive) obstacles to innovation and strengthening the knowledge base through investment in education, research and industrial sites in Africa.
\end{abstract}

Keywords: Innovation Policy, Africa, Nigeria, Investment, Productivity, Science Parks, Business Clusters, Economic Zones, Inventions, Free Trade Zones, Cognitive Revolution, Industrial Revolution, Infrastructures, Technology, Research and Development, Venture Capital

\section{Introduction}

Essentially, the development of any society depends on the transformation of the resources into useful products and services. On one hand, this transformation process deals with the elements of engineering. On the other hand, the management of transformation process deals with productivity and minimization for wastage. Consequently innovation (particularly technological innovation) is rightly seen as a key to economic and social development. It is therefore anticipated that the government (acting as a gardener) supports the innovators by providing appropriate financial and other measures (watering the plant) by removing regulatory, institutional or competitive obstacles to innovation(removing the weeds and pests) and by strengthening the knowledge base through investment in education and research (fertilizing the soil). However, innovations come from the entrepreneurs who make them happen and ultimately depend on society's receptiveness. In other words, innovation is fundamentally a social process and technological innovation is often accompanied by organizational and institutional innovation at both micro and macro levels. As a key driver of economic development as well as the principal tool for coping with major global challenges; innovation is basically a new and better product or service or a new and more efficient (or less costly) way of producing, delivering or using that product or service. Therefore, innovation provides a means for getting more output or welfare from limited resources. Indeed, innovation has been critical for the rise in population and in per capita income and welfare. Consequently, the first major technological innovation (in the world history) was probably the development of agriculture as far back as 9000BC. Subsequently, the development of pottery occurred in 6000BC.

However, other important innovations were the development of the plow and irrigation between 5000BC and 4000BC (which facilitated growth of the world population). Yet, the developments of metallurgy and writing dates from around $3000 \mathrm{BC}$ while the development of mathematics dates from about 2000BC. Between 1000BC and 1AD, the peak of Greece and Peak of Rome were discovered. And between $1000 \mathrm{AD}$ and $2000 \mathrm{AD}$, there have been several successive innovations: Black Plague, New World Discovery, $2^{\text {nd }}$ Agricultural Revolutions origin, Industrial Revolution Origin, Watt Engine Invention, Rail Roads Origin, Germ theory, Telephone Electrification Invention, Automobile Invention, Malaria War, Penicillin, DNA Discovery, High Speed Computers, Nuclear Energy, Man on Moon, Personal computers and Genome Project. However empirical 
observations have shown that between 1400 and 1500AD, global population and per capita income increased simultaneously and this growth resulted from the convergence of many factors: better hygiene, more efficient ways to harness wind and water power to augment human and animal energy as well as advances in agricultural techniques (like irrigation, improved seeds and multiple cropping). Again advances in ship building and navigation technology (including the astrolable and the compass) led to increased trade while expanding markets and specialization. In the same way, both population and per capita incomes began to rise from the AD1800's onward, and this tremendous growth was in large part led by the development of the steam engine, which basically enable human kind to harness fossil fuel energy for productive tasks.

Consequently, the resulting augmentation of power brought about the industrial revolution with a corresponding proliferation of productive activity and expansion of products and services brought to the market.

Empirically, systemic transitions have taken place throughout history and these changes work their way through society over more than a century and the pace limited only by the human factor. In other words, change cannot proceed faster than the speed of human adaptation to the new technologies and succeeding generations define the rhythm of adaptation. Thus, in the early middle ages, in the out-going industrial revolution, and the present cognitive revolution, the change in technologies can be described in terms of four poles that is usually presented on a symbolic cross as shown in figure 1.1

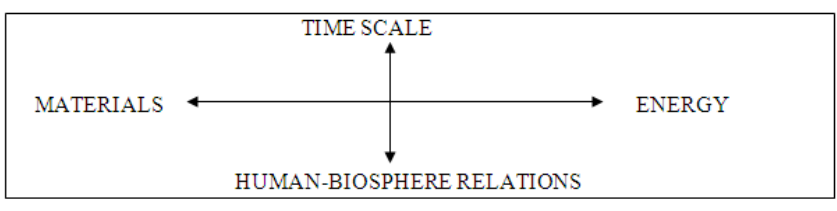

Figure 1.1. Global technical System Structure
Specifically, the basic innovation in the middle ages, industrial revolution and cognitive revolution are activated by these four poles as shown in figures $1.2 \mathrm{~A}, 1.2 \mathrm{~B}$ and $1.2 \mathrm{C}$ respectively.

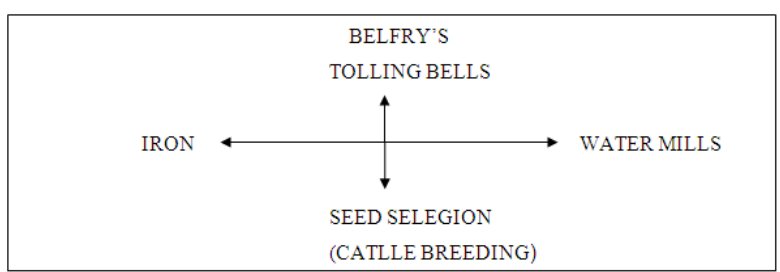

Figure 1.2A. The Middle Ages

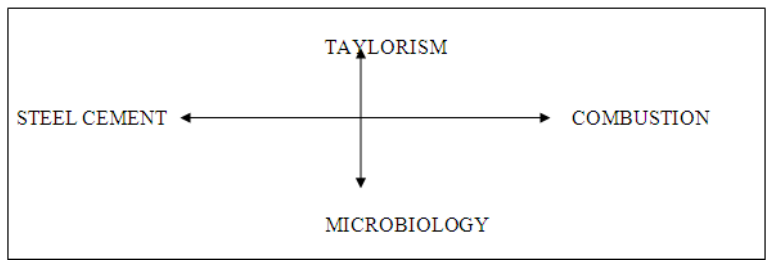

Figure 1.2B. The Industrial Revolution

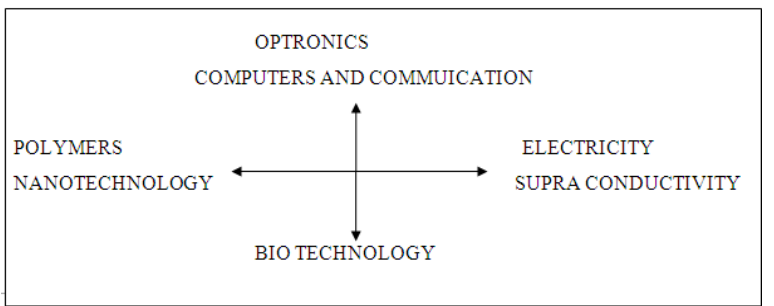

Figure 1.2C. Cognitive Revolution

In fact, the industrial revolution includes a series of inner technological revolutions (which may be called the second order revolutions) which go along with infrastructure and institutional changes (as shown in tables $1.1 \mathrm{~A}, 1.1 \mathrm{~B}, 1.1 \mathrm{C}$ AND 1.1D).

Table 1.1A. First Industrial Revolution

\begin{tabular}{lll}
\hline Time Period & New Technologies (Redefined Industries) & New (Redefined Insfrastructures \\
\hline From 1971 In Britain & Mechanized cotton industries, wrought from machinery & $\begin{array}{l}\text { Canals and waterways, turnpike roads, water power } \\
\text { (improved water wheels) }\end{array}$ \\
\hline
\end{tabular}

Table 1.1B. Age of Steam and Railways

\begin{tabular}{lll}
\hline Time Period & New Technologies (Redefined Industries) & New (Redefined Insfrastructures \\
\hline $\begin{array}{l}\text { From } 1829 \text { in Britain, spreading } \\
\text { to Continental Europe and United }\end{array}$ & $\begin{array}{l}\text { Steam engines and machinery made from iron for many } \\
\text { industries, including textiles, railways, steamships iron roads, national telegraph mainly along railway } \\
\text { States }\end{array}$ & $\begin{array}{l}\text { lines, universal postal service, worldwide sailing } \\
\text { and coal mining playing a central role in growth }\end{array}$ \\
\hline
\end{tabular}

Table 1.1C. Age of Steel, Electricity and Heavy Engineering

\begin{tabular}{|c|c|c|}
\hline Time Period & New Technologies (Redefined Industries) & New (Redefined Insfrastructures \\
\hline $\begin{array}{l}\text { From } 1875 \text { in the } \\
\text { United States and } \\
\text { Germany over Taking } \\
\text { Britain }\end{array}$ & $\begin{array}{l}\text { Cheap steel, full development of steam Engines For Steel } \\
\text { Ships, Heavy Chemistry And Civil Engineering, Copper } \\
\text { And Cables, Caned And Bottled Food, Paper Packaging }\end{array}$ & $\begin{array}{l}\text { Worldwide shipping in rapid steel steamships, Worldwide } \\
\text { railways, steel bridges and tunnels, worldwide telegraph, } \\
\text { national telephone, electrical networks for lighting and } \\
\text { industrial use }\end{array}$ \\
\hline
\end{tabular}


Table 1.1D. Age of Oil, Automobile and Mass Production

\begin{tabular}{lll}
\hline Time Period & New Technologies (Redefined Industries) & New (Redefined Insfrastructures \\
\hline $\begin{array}{l}\text { from } 1908 \text { in the } \\
\text { United States } \\
\text { spreading to Europe }\end{array}$ & $\begin{array}{l}\text { Mass produced automobiles; cheap oil fuels, petrochemicals, } \\
\text { internal combustion engine for automobiles, transportation tractors, } \\
\text { airplanes, war tanks electricity and electrical home appliances, }\end{array}$ & $\begin{array}{l}\text { Netwiversal electricity for industry and home; worldwide } \\
\text { refrigerated and frozen foods }\end{array}$ \\
\hline
\end{tabular}

However, the industrial age is the result of a disruption that is now coming to an end. Regrettably, during the $17^{\text {th }}$ and $18^{\text {th }}$ century, the overexploitation of European forests led to their exhaustion and consequently, the economy had to turn to non renewable source of energy: coal and oil. Unfortunately, this transition disregarded the equilibrium between humans and the biosphere that for millennia been the sacred rule of survival. But fortunately with the cognitive revolution, the order of magnitude of the time scale shifts from one-tenth of a second to one-billionth of a second (100 million time thinner) in a first stage and probably even a million times thinner again(fem to second $10^{-15}$ ) with optical commutation. Furthermore, materials are now elaborated at molecular level for polymers and even at atomic level (one billionth of a meter) with the development of nanotechnologies.

By manipulating genetic codes, biotechnology also reaches that level of detail. And perhaps to stimulate the understanding (and financing) of these fields of research, policy makers have promoted the term CONVERGING TECHNOLIGES AS A NANO-BIO-INFO-COGNO COMPLEX.

Here, what are new are the order of magnitude and the speed of change. In fact, change has occurred so quickly that the average citizen does not realize that his cellular phone computes in nanoseconds (as does her laptop). Similarly, a car's global positioning system (GPS) can transform the signals from the satellite to a position on earth with a degree of precision of less than one meter in the time scale. Clearly, if humans do not succeed in rebuilding a sustainable equilibrium with nature; what is called civilization will inevitably collapse. However, this question concerns not only non renewable mineral resources but also biodiversity now under strong pressure from human activities. Thus, the point made is very clear: nature can survive without humans but humans cannot survive without nature.

Indeed, given the large stock of knowledge in the world and its rapid expansion, African nations would seem to have tremendous potential for moving up rapidly to the world technological frontier. In other words, the key innovation priority for African nations is to acquire and use knowledge that already exits, which is clearly less costly and less risky than creating new knowledge. While some of this knowledge is protected by intellectual prosperity rights and therefore would have to be purchased an enormous amount is in the public domain. Therefore, polices that facilitate access to global knowledge are critical and how well Africans use this form of information will depend not only on their policies but also on the support of the country's institutions and the effectiveness of those institutions and the people in them. While the forces of international competition are undoubtedly an important catalyst for improving economic performance, purely domestic factors have much to contribute. Yet other important determinants of disembodied productivity growth stem from characteristic of an economy that is not related to the trade regime. Thus, the impacts of education, health, nutrition, and industrial relations on labor productivity can all be shown to exert some effect on productivity. This paper therefore concentrates on a few major recurring themes that have been prominent in the emerging literature on innovations as relevant in the global business context. Section two discusses the innovative enterprises and sites. Section three considers Nigerian business cases. The innovation policy strategies are examined in section four and conclusions are presented in section five.

\section{Innovative Enterprises (Sites)}

Practically, innovation is a global phenomenon that is not limited to wealthy but represents tremendous opportunities and challenges. This, specific innovations are the foundation of competitive industries (source of exports and substitute for imports). Therefore, the promotion of competitive industries requires the mastering of all areas involved in the quality, competitiveness and delivery of products; design, production process, certification and standards, marketing, transport, etc. Subsequently, these stages can often be customized for domestic and regional markets and then scales up to meet the demands and requirements of international markets. Here, we look at how innovation is nurtured and sustained through formal and informal interactions and through partnerships between the private and public sector. Prototype examples are therefore used to analyze the dynamics of innovation in specific instances and how these dynamics result in competitive industries. Essentially, the agricultural sector can offer African nations important opportunities. By starting from the production and export of commodities, countries can grow gradually climb up the value chain and develop value added activities (a rise that requires strong organizational capabilities in all concerned actors). On the other hand, the development of manufacturing export industries can benefit from the involvement of foreign investors and imports of capital goods as these facilitate the gradual transfer of competencies and technologies. Similarly, in the services sector, information technology has created considerable opportunities: software services, business process outsourcing and call centers. 
However, success in agriculture, manufacturing or services is a long-term process that requires tremendous learning and discovering. Here, success can therefore be achieved by analyzing the under listed seven key dimensions of the innovation system:

\begin{tabular}{|c|c|c|}
\hline (A) & $\begin{array}{l}\text { VISION } \\
\text { (LEADERSHIP) }\end{array}$ & $\begin{array}{l}\text { Political system and stability; } \\
\text { strategic focus. }\end{array}$ \\
\hline (B) & $\begin{array}{l}\text { FRAMEWORK } \\
\text { CONDITIONS }\end{array}$ & $\begin{array}{l}\text { Overall economic and institutional } \\
\text { regime; taxation and incentives } \\
\text { competition. }\end{array}$ \\
\hline (C) & $\begin{array}{l}\text { EDUCATION } \\
\text { (RESEARCH) }\end{array}$ & $\begin{array}{l}\text { Human Resource capacities; training; } \\
\text { higher education institutions. }\end{array}$ \\
\hline (D) & INFRASTURTURE & $\begin{array}{l}\text { Business support and services; } \\
\text { finance and venture capital; } \\
\text { information and communication } \\
\text { technology. }\end{array}$ \\
\hline (E) & $\begin{array}{l}\text { INDUSTRIAL } \\
\text { SYSTEM }\end{array}$ & Type and mix of companies \\
\hline (F) & INTERMEDIARIES & $\begin{array}{l}\text { Information brokers and } \\
\text { disseminators; research institutions }\end{array}$ \\
\hline (G) & DEMAND & $\begin{array}{l}\text { new markets; finding a niche; } \\
\text { opportunity }\end{array}$ \\
\hline
\end{tabular}

Indeed, agriculture has a powerful and pervasive place in nearly every nation of the world. Thus, the production, trade, and consumption environment for agriculture and agricultural products is increasingly dynamic and evolving in unpredictable ways. Here, if farmer's and companies are to cope, compete and survive, they need to innovate continuously. Consequently, for the foreseeable future, the growth strategy for most agriculture based economies has to focus on improvements. Even where the development of world class manufacturing and services industries is unlikely (at least in the short to medium term) agriculture needs to tackle fundamental problems: poor infrastructure, inaccessible markets, poor storage methods, lack of processing facilities and the relative lack of fertilizer and the relative lack of fertilizer and seeds. Yet some countries have initiated programs to strengthen basic technology and capacity building to improve agriculture and rural livelihoods. In Africa (particularly) while agricultural firms can and do export, their numbers are relatively small. Because exporting itself increases learning and raises the quality of product; exporting firms can achieve rapid productivity growth. Therefore, when domestic markets are too small to support competition, learning from exporting is a powerful tool. It is therefore increasingly acknowledged that agriculture has changed significantly over the past three decades with new markets, innovations and roles for the state, the private sector and civil society. In this new agriculture, private entrepreneurs (including many small holders) are linking producers to consumers and are finding new markets for staple food crops and export commodities. Thus, this vision of agriculture requires rethinking the roles of producers, private sector and state. Here production is carried out by both small holders (often supported by cooperative organizations) and by labor-intensive commercial farming (offering a more productive and efficient model). Again, the state's role (through enhanced capacity and new forms of governance) is to correct market failures, regulate competition and engage strategically in public - private partnerships.

Basically, the new agriculture (with its increasingly complex agricultural markets, networked knowledge and competitive advantage linked to capacities for knowledge application) emphasizes institutions, coordination and improved links among the main actors of the innovation system. Here as a complementary frame of reference, the Agricultural innovation system (AIS) approach recognizes that many types of innovation (related to technology, organizations ad partnerships, processes, products and marketing) can take place at any time in different parts of the overall system. Clearly promoting innovation in agriculture requires coordinating support for agricultural research, extension and education; fostering innovation partnerships and links along and beyond agricultural value chains; and enabling agricultural development. This AIS approach surely emphasizes technology and knowledge generation and adoption rather than simply strengthening research systems and their outputs. Similarly, it looks at the whole range of actors and factors and needed for innovation and growth and assumes that innovation derives from as interactive dynamics, process that increasingly relies on collective action and multiple knowledge sources at diverse scales to leverage the resources of the private sector, civil society and farmers associations. Thus the structure, quality and dynamics of AIS drive the agricultural sector as a whole. In other words, it is the interplay of all the actors and institutions involved (characteristics of the industry, transport conditions, policies and the enabling environment) that determines the level of innovation and competitiveness that emerge (as shown in figure 2.1).

However, as the key interface between markets and rural households, agribusiness firms link agriculture to industry and respond to opportunities growing out of the liberalization of economies and the globalization of trade, thereby assisting a country's agricultural producers in moving up the value chain in various markets.

Again, manufacturing is a very wide-ranging sector that encompasses the production of such diverse production as automobiles, jet engines, household appliances, clothes, jewelry and paper products. On the other hand, services make up about seventy percent of global GDP and consist of an even more diverse set of activities than manufacturing; banking, retails, insurance, education, media, healthcare, information technology, hospitality, law, tourism and consulting are just some examples of activities within the service sector. Unfortunately, a major constraint to the competitiveness of many firms is the absence of right kinds of institutions to support technology change. Here, such institutions carry out research and development evaluate testing, quality assurance, enforcement of laws and standards, networking and information dissemination. Again, since the market alone in not sufficient to promote the organizational interactions required for innovation, the 
state must create new institutions where they do not exist; restructure institutions in response to change and reshape interactions among firms and organizations through the use of incentives. Yet, the most essential factors for influencing technological catch-up are environment that notes the ability to learn and apply new technologies and the facilitating hand of government. However, it is clear that a wide range of public policies can foster or impede innovations that lead to productivity gains, which in turn translate into greater competitiveness. But it is equally clear that the policies that are most relevant will vary from country to country and be determined by local values, institutional cultures, business conditions and key production inputs in particular subsectors. Consequently, although African nations can often learn useful lessons from the successful experiences of other nations, they will have to design their own strategies. But their choices of what to use and what to discard will and should be conditioned by local values, institutional capacities and economic conditions.

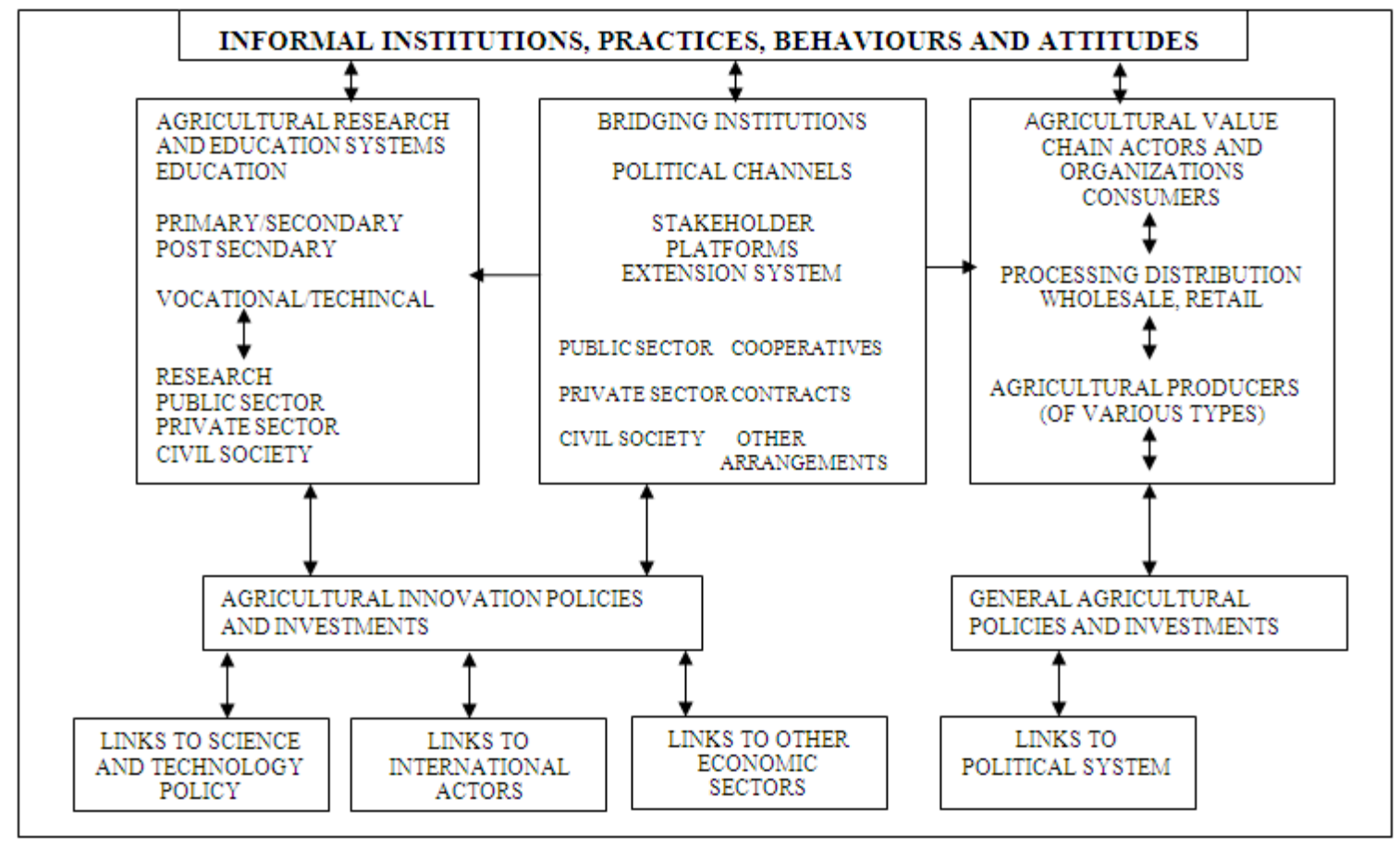

Figure 2.1. Agricultural innovation systems (AIS)

Empirically, local innovation is of particular interest because innovation has its foundations in micro economic (local) processes (proximity, networks, density, and diversity) and because economic globalization is increasingly important. Obviously, this concept fosters competition between local units of production, promotes the new techniques that enable the international division of production processes; increases the efficiency of transportation and improves information and communication technology (ICT) infrastructure. And yet, because of the connection between local innovation and success in institutional markets, localities have a strong rationale for developing a strategy for increasing innovation in targeted sites: special economic zones, science parks, clusters and even cities. Essentially, special economic zones (SEZs) are often associated with low range, low skill production; but experience shows that they can stimulate innovation, particularly in a context of a mediocre but evolving investment climate. Again, science parks are increasingly popular for developing employment opportunities for recent tertiary graduates as well as spanning local business creation. Similarly, clusters (silver bullet for boosting innovation) are networks of firms whose function may be favored by certain government policies. Here, a special economic zone is defined as a geographically delimited area with a single management or administration and a separate customs area (often duty free) where streamlined business procedures are applied and where firms physically located within the zone are eligible for certain benefits (such as tax exemption for a number of years, accelerated depreciation, and investment).

Operationally, SEZs can be seen as a way to attract multinational companies (MNCs) and create local jobs, even when the general business environment is poor. In fact, their attractiveness comes not only from their direct economic benefits (such as employment and foreign currency generation) but also from their indirect benefits such as technology transfer, potential backward linkages with local firms and stimulation of local innovation. From the host country's perspective, the benefits of SEZs fall into two categories: direct benefits (foreign exchange earnings, FDI attraction, and increased government revenue export growth) and indirect dynamic benefits (upgrading skills of workforce and management, technology transfer, demonstration effect, export diversification) that enhance the trade efficiency of domestic firms and knowledge of 
international markets. However, the creation of a "catalyst" appears to depend on whether the SEZ becomes partially integrated into the local economy through linkages with enterprises outside the SEZ. Consequently, the SEZ can increase the ability of domestic firms to respond to new opportunities, favor technology transfer through people and stimulate the competitiveness of domestic firms. The host country can equally experience significant spill over effects from FDI. Specifically, horizontal spill over include technology "leakage" from MNCs to local firms in the same industry (which occurs in various ways). On the other hand, vertical spillovers (backward links) take the form of positive externalities through the supply chain. As a channel through which information and material flow between a firm and its suppliers, these links create a network of economic interdependence. That is, multinationals located within the SEZ may want to transfer technology to their local suppliers outside the SEZ to achieve lower production costs, increased specialization and better adaptation of technologies and products to local environments. Yet in practice, horizontal and vertical linkages benefit the local economy through increased output and employment, improved production efficiency, technological and managerial capabilities and market diversification. Although these links can be extremely important for fostering local innovation, the onus of developing them should not be on the firms inside the SEZ. Generally, we present the two main ways aimed at encouraging innovation through special economic zones:

(A) Fostering links: Attractive conditions and incentives that make it cost effective to use local content.

(B) Increasing domestic capabilities: Investment in training and technology upgrading of domestic workforce to match; allowing or encouraging domestic firms to have same access to hardware (machines) to improve production.

Essentially, science parks are popular for developing local capacity for innovation and for creating employment for tertiary and technical graduates. Thus, a science park is defined as an organization and property development managed by specialized professionals who seek to increase the competitiveness of their city, region or territory of influence. This park does so by concentrating mature technology, science or research related business (such as MNCs) fostering collaboration among them and knowledge based institutions, and transferring knowledge to the market place. Traditionally, science parks are often associated with or operated by institutions of higher education or research institutes. Typically, the science park can be defined by four functional components and several physical components.

Here, the functional components include:

(i) Businesses: Established MNCs, domestic companies and start ups in various combinations

(ii) Knowledge providers: University research and education infrastructures, applied research labs and facilities usually handled by public bodies.

(iii) Industry support services: Business incubators and enterprise development areas (as managed by private operators).

(iv) Financial support services: Venture capital, regional development agencies or banks.

On the other hand, the physical components include infrastructure development, office buildings, meeting rooms, transportation, power and ICT connectivity. Therefore, the combination of functional and physical components promotes economic development and competitiveness by creating new business competitiveness opportunities and adding value to mature companies, fostering entrepreneurship, incubating new innovative companies, generating knowledge-based jobs, and building attractive spaces for knowledge workers. In fact, many countries have recently created science parks to obtain technology transfer, skills, capital and exposure to MNC research for both universities and domestic companies to create employment for graduates with advanced degrees who often do not find employment otherwise and to slow brain drain. While early parks were often simply real estate developments, recent generations have focused more on services (particularly on business services to start - up companies, as well as leisure services for tenants) to increase their impact and attractiveness to businesses and their employees(as shown in table 2:1)

Operationally, a successful science park should be integrated into the host city and several relevant factors need to be taken into account. Land policy, access ease, research laboratories (universities) presence, and affordable housing. Thus, the idea of integrating science parks into existing local networks and city or regional development strategies is good. Science parks are located near business cluster and have sometimes even spurred its development (such as the United State silicon valley's science park.) Critically, those considering whether to create a science park should weigh (among other factors) its location and design as well as ways to support users; Link with networks; secure financing; and ensure sustainability. Yet, science parks can also be designed as part of an overall city or territorial economic and infrastructure development strategy. However, a science park will typically go through various phases in its design and build out strategy; planning; action; commercialization and promotion as well as evaluation and performance indicators. Operationally, science park clients are typically technology - intensive small and medium enterprises (SMES) or multinational companies (MNC) and therefore require a range of services particularly for SMES in their early stages of development. Thus, quality and cost effectiveness of services are important for attracting prospective businesses or tenants. Essentially, a science park is a costly investment, requiring funding at different stages of development (from conception to operation and production). It is therefore necessary to finance both the physical infrastructure and some or all of the funding for the projects and companies located in the science park. However, funding options for infrastructure depend primarily on the institutional arrangements of the park and 
the respective roles of the public and private sectors. In other words, there are three basic funding options for physical infrastructure in science parks: Public funding, Joint Public/Private funding, and loans and guarantees. Again, the financing of companies and projects within the park can include public seed money and start-up capital, as well as private provision of funds such as venture capital. Yet, to be financially sustainable, a science park must drive a certain amount from various revenue streams: use or sale of physical infrastructure, use of technical areas, use of technological facilities and services. Again, a science park should contribute to broader economic objectives, including local employment and the increased competitiveness of local firms. And clearly, a successful science park depends on a wide community of support and participation. In other words, it should seek to balance the interests of all major stakeholders, including the areas industrial, scientific and financial leaders; representatives of business associations; potential government; community organizations; and educational and academic institutions. Realistically, these stakeholders should participate in the strategic positioning of the science park and develop a sense of shared ownership and responsibility in the implementation phases. Here, beginning with a workshop or conference, this effort can continue through involvement in research and surveys on available local and national resources.

Table 2.1. Science parks: over time evolution

\begin{tabular}{|c|c|c|}
\hline Early Parks (Stand-Alone Physical Space & 1990's: Connections & $\begin{array}{l}2000 \text { And Beyond; Economic Driver for the } \\
\text { Region }\end{array}$ \\
\hline a. Real estate operations & $\begin{array}{l}\text { I. Anchor with R \& D facilities aligned with } \\
\text { industry focus of park. }\end{array}$ & $\begin{array}{l}\text { 1. More and more mixed use development, } \\
\text { including commercial and residential }\end{array}$ \\
\hline b. Campus - like environment & $\begin{array}{l}\text { ii. Innovation centers and technology } \\
\text { incubators more common }\end{array}$ & $\begin{array}{l}\text { 2. Increased focus and deeper service support to } \\
\text { start-ups and entrepreneurs. }\end{array}$ \\
\hline c. Focus on industrial recruitment & $\begin{array}{l}\text { iii. Multitenant facilities constructed to } \\
\text { accommodate smaller companies }\end{array}$ & 3. Less focus on recruitment \\
\hline $\begin{array}{l}\text { d. Few (if any) ties between tenants and } \\
\text { university or Federal laboratories }\end{array}$ & $\begin{array}{l}\text { iv. Some support for entrepreneurs and start- } \\
\text { up companies provided directly. }\end{array}$ & $\begin{array}{l}\text { 4. Formal accelerator space and plans for } \\
\text { technology commercialization roles emerging }\end{array}$ \\
\hline \multirow[t]{3}{*}{$\begin{array}{l}\text { e. Little business assistance and few services } \\
\text { provided }\end{array}$} & & $\begin{array}{l}\text { 5. Greater interest on part of tenant firms in } \\
\text { partnering with universities. }\end{array}$ \\
\hline & & $\begin{array}{l}\text { 6. Universities more committed to partnering with } \\
\text { research park tenant. }\end{array}$ \\
\hline & & $\begin{array}{l}\text { 7. Amenities from day care to conference and } \\
\text { recreational facilities added. }\end{array}$ \\
\hline
\end{tabular}

Generally, CLUSTERS have been viewed as an instrument for enabling firms to join their efforts and resources with knowledge sources and government for greater regional, national, and international competitiveness. Although clusters are not necessarily innovation systems and innovative clusters are not necessarily high technology clusters, cluster initiatives may be one of the most effective means for producing an environment conducive to innovation. Precisely, a cluster is a geographic concentration of interconnected companies in a particular field with links to related organizations such as trade associations, government agencies, and research and educational institutions. Precisely, it gives rise to external economies (specialized suppliers) or pools of sector specific skills and farms development of specialized services in technical administrative and financial matters. Comparatively, clusters tend to have a sectoral specialization and do not have urban development or physical infrastructure. Again, they need not have hightechnology focus; and tend to be larger and have more stakeholders. Unfortunately, the presence of potential benefits from cluster initiatives does not in itself justify policy intervention. Yet, a yes or no view on the issues of public intervention can be counterproductive. In other words, the diversity in the emergence and support for clusters argues for pragmatism and caution. In fact, Clusters can emerge and develop as a legacy of the past or as a more voluntary attempt to create a new future or both. However, it is difficult for policy makers to simply create a successful cluster. Consequently, a spontaneous cluster may be more likely to foster new habits, learning practices, links, and continuous innovation than constructed clusters. Therefore, once identified, clusters can be nurtured through policy intervention.

However, before any policy intervention, it is important to understand the local economy and map existing, potential, or dormant clusters. Thus, focusing on clusters can in fact help local and national governments better understand how their local economies work. Indeed, by looking at an economy through the lens of various clusters, local governments can move accurately identify market imperfections; detect systemic failures and better tailor policies. Here, once clusters are identified, more sophisticated tools can model and map them and the relations among cluster members. Practically, clusters evolve, operate and are embedded in specific geographic, cultural, social, regulatory, spatial and institutional environments. Thus, in certain circumstances, government policies that facilitate networking, catalyze comparative advantages, and build effective institutions, as well as 
nurture the more general environment for innovation; can help a cluster gain momentum and improve both its efficiency and its capacity for innovation. Consequently, policies used to support clusters fall broadly into two main categories: improving cluster dynamics and improving the cluster environment (plus evaluation of cluster support mechanisms and initiatives). However, firms in clusters do not necessarily share or circulate an economically optimal amount of knowledge and information. Policy measures (broker policies) therefore attempt to establish an effective framework for dialogue and cooperation between firms and between firms and relevant public sector actors or other agencies. Basically, these measures include the following: Creation of platforms for dialogue and networking between creation of knowledge - enhancing partnerships between firms and other institutions; economic intelligence; statistics and data. Again, specific public policies can also support the upgrading of skills in clusters; links with vocational training programs; cluster skills centers and external learning. Similarly, some services to innovative firms are particularly relevant in a cluster context; cluster technology centers and cluster - based incubation.

Indeed, a common strength of clusters is their ability to pool resources and efforts to reach markets effectively. Therefore, policy makers often help by making data and information on markets (as well as technologies) available to clusters. Here, further means of improving a cluster's efficiency include international links, different framework conditions and evaluations of the cluster's performance. However, framework conditions for optimal cluster functioning include macroeconomic stability; product and factor markets; educational systems; and physical, institutional and governance structures and conducive to innovation. Yet, the interplay between formal practices (contracts, structured hierarchies, and public regulations) and informal practices (norms, routines, traditional authority and expectations) is complex. Here, critical issues include whether there is conflict or complementarily between formal institutions and informal value systems. And because trust is particularly important to cluster initiatives, those that can reinforce social capital and the attitudes that influence trust between stakeholders are equally important. Consequently, through international surveys of cluster initiatives (http.//www.clusterresearch.org) data are available to benchmark cluster initiatives. Again, the creation of an online survey tool enables local and regional governments worldwide to use the survey results to take stock of how cluster stakeholders view their situation and what can be done to improve it (http:www.clustercompetitiveness.org).

Besides the specific tools available for fostering innovation, such as SEZs, clusters and science parks, cities can also learn from both the positive and negative factors that can affect innovation in an urban context. Indeed, such lessons are crucial in African countries, where they may help shape the creation and implementation of dedicated innovation policies and address weakness in infrastructure and in urban planning, human capital, governance and image issues. Unfortunately, a major bottle neck of firm activity in Africa is the low density, multimodal structure of their cities, aggravated by the limited availability of transportation. On the demand side, high transportation costs and low consumer mobility inhibit market access for firms. Any yet, on the supply side, poor infrastructure hampers the constitution of interfirm networks and clusters, while intensifying the mismatch between the employment centers and the workers housing. Again, poor transportation infrastructure implies that people use cars, private minibuses, tuk-tuks, motorbikes; thereby creating close to anarchy on slam roads and exacerbating traffic congestion and pollution. Thus, proactive urban planning policies can therefore be considered important to enhance for more general citywide innovation policy actions, based on principles that explicitly aim at enhancing competitiveness. As for governance, city innovation policies should ideally be part of the larger framework of national strategies for innovation. Here, while implementation may take place locally, such important measures as taxation, trade policy, public funding of research, and regulation of the business environment will take place nationally. Obviously, this factor may be challenging in African countries where institutional, financial and political constraints may limit the autonomy of planning agencies or local authorities. However, the renovation of old town buildings or the launching of development programs can modify a city's identity and provide physical evidence of dynamism at moderate cost, especially as the private sector can be associated with the project. Thus, as part of an all-compassing branding strategy, a cultural event can increase a city's visibility (while providing local works and new skills).

\section{African (Global) Business Cases}

Prior to 1999, when successive Nigerian Military governments appeared to be an economic self destruct mission through massive fiscal mismanagement (and the unstable policy this engendered) a few Nigerians risked everything by investing extensively in the country's as well as creating jobs, wealth and economically empowering the people. However, the efforts of some big investors help sustain the economy; thereby giving new investors hope and the belief that patience is truly a virtue in investment (with innovations). Subsequently, with the emergence of Obasanjo administration (in 1999), one of their cardinal objectives was to revive the comatose economy. Operationally, among their strategies to achieve that was to encourage entrepreneurial activities by selling government stakes in business in Nigeria to both local and foreign investors through commercialization and privatization. These measures were therefore envisaged to turbo charge the economy by promoting competition, efficiency, productivity and human development. Here, with the privatization of the electricity sector underway, we notice a frenzy of activity from allied sectors as they position 
themselves to benefit from the bounty. Regrettably, the comatose state of the energy sector in Nigeria is currently giving manufacturers a tough time. In fact, as companies close down due to energy crisis, thousands lose their jobs and the nation counts its losses in billions of dollars. Similarly, Nigerians have spent over N1 trillion to purchase generators; and by adding this cost to the maintenance costs and the cost of fueling, it adds up to tens of trillions of naira lost yearly. Again, the cost to life and environment is even greater. In fact, everywhere you go, the nation's landscape is dotted with millions of generators belching out carbon monoxide, which, apart from contributing to global warming; has caused the death of many from inhaled fumes). Thus, considering the huge human and material cost of an unstable power supply to the ceremony; it was obvious that the energy sector in Nigeria needs revival.

Consequently, the revival button was activated in 2000 when (as part of the economic reforms of the Obasanjo administration) government agrees to privatize the energy sector to boost economic activity. Thus, in 2001, a new power policy was formulated leading to the entry of Independent Power producers (IPPs). However, in 2004, government unbundled the National Electric Power Authority (NEPA), paving the way for the Power Holding Company of Nigeria (PHCN) to replace NEPA in 2005. Operationally, the power sector has been broken into three major sub-units; Power generation, transmission and distribution. This has therefore given birth to eighteen companies within the system: eleven distribution companies (Dis Cos), six generating companies (Gen Cos) and a transmission company (Transys Co). To facilitate acquisition, the existing distribution companies under PHCN should retain their current names Abuja distribution zone, Benin distribution zone, Enugu distribution zone, Ibadan, Jos, Kaduna, Kano, Lagos, Port-Harcourt and Yola distribution zones. However, Lagos has two distribution units (Eko and Ikeja distribution zones). Here, as part of the reform strategy, an Electricity Power sector Reform Act (EPSR) was promulgated. Essentially, this act is to ensure that the interest of customers and investors is adequately protected. Similarly, Nigerian Electricity Regulatory Council (NERC) was inaugurated; and it acts as a regulatory body to ensure competitiveness, uniformity in pricing and adherence to technical standard. Basically, NERC will be responsible for the issuing of licenses to all market participants while the business of power and energy supply will be run by the private sector; although within prescribed legal and technical framework. And to break the monopoly in the sector, government will be restricted to enabling the success of the reforms by making sure the private bodies that will run the sector remain within the Legal and social framework of the agreement to deliver the highest productivity.

Operationally, the investment opportunities are vast and available in power generation, transmission and distribution. Obviously, the companies themselves are being privatized or concessioned out; and the potential operators are going to need billions of naira to buy the concessions and refurbish the assets. Thus, many of the operators are raising equity capital through private placements, private equity funds and other sources. Again, companies already operating in this sector (such as ADSWITCH and JOHNHOLT) are positioned to pick up additional businesses for their cable, transformers and other electrical power equipment as investment in the industry steps up. Similarly, the large construction companies are likely to benefit as new civil works are commissioned for power stations, electricity substations, transmission networks and oil and gas pipelines. Equally, a whole new supply chain is likely to emerge, as companies develop to provide services to the new electricity operators. Specifically, information technology, training, prepay voucher distribution are just a few areas where new and existing entrepreneurs will be developing their businesses. Of course, not to be left out are the companies that will benefit from improved power supply. Here, many industries that are currently struggling under the weight of poor power should see margins and profitability increase as they shut down their expensive diesel plants. We therefore believe that the power sector reforms have the potential to deliver the major boost to the Nigerian economy.

Operationally, the principal activity of CUTIX PLC is the manufacturing (marketing) of electrical, automobile, telecommunications wires (cables) and related products. Its distributors and customers are strategically located in core business creations across the country. With growing net profits by about $19.5 \%$, its half - year (2006) results showed an impressive top line growth of $35 \%$ with over $200 \%$ growth in net profits culminating in a net profit margin of $15 \%$. The management therefore has indicated that growth resulted from increased capacity in terms of manpower and equipment acquisition. Thus, in the years ahead, the company plans to roll out more training and skill certification programmes to enhance productivity; while the company's core strategies are to increase the range of cables manufactured by it and take its products into new markets. Yet, a renew of the company's financial performance shows a total debt/total asset ratio of $56 \%$ while returns on equity and capital employed of $33 \%$ and $57 \%$ respectively.

$W A P C O$ engages in the manufacture of building and construction materials and the company now rides on the benefit of restructuring. Here, the increased plant capacity of more than 1.5 million metric tons drove the performance, and the company's strategy is a further increase in plant size considering the shortage in supply of cement. It is therefore believed that the growing public and private sector investment in building and construction will drive its performance over the next few years. Generally, the company's performance ratios have1 shown strong market performance ratios have good oversight on costs. In fact, operating $35 \%$ while net margins are $27.3 \%$ with return on equity of $59 \%$.

R. T. BRISCOE was incorporated in Nigeria (1957) as a 
private limited liability company; and the core business of the company remains the sale and serving of motor vehicles (accounting for $94 \%$ of revenue). Its other business include importation and sale of Atlas Copco generators; forklifts and compressors; the construction and maintenance of cell sites for telecommunications companies and facilities; and project management (including property development). Eventually, the company has plans to design a Nigerian car and thus the company is making arrangements to build an assembly plant for Toyota and Ford vehicles. Yet, the tremendous growth in revenue can be traced to its after sales service; and the presence of spare parts for its range of products has enabled the company to meet the needs of customers.

$N C R$ which was established in 1884 and listed on the stock exchange in 1979, provides products and services which include computer marketing and support services, design and printing of business forms, and sales of computer media. In the last few years, the company has consistently pursued a policy of improving its revenue base with significant progress in the core areas of its business. Again, the accumulated losses in the previous years that precluded the company from declaring dividends have been completely reversed the company has also restructured its operations and is now fully focused in its core business of information technology. In order to consolidate its market share, it diversified into ATM network monitoring and management, ATM camera solution, ATM advertising solution, among other applications. However, faced with the challenges of expansion, it plans to open new support centres to complement existing ones.

Flour Mills of Nigeria Plc is one of the largest conglomerates in Nigeria. Its activities span flour milling, pasta manufacturing, port operations cement trade and manufacturing, fertilizer, blending, bags and other packaging materials manufacturing and agricultural business. Since 1960, FMN has grown into a market leader with popular and highly recognizable brands and an extensive distribution network. In fact, FMN's expanding capability and innovativeness has been a strong force in growing the business. It successfully installed and commissioned its gas - powered generators (with total generating capacity of 21 megawatts). Specifically, the conversion from diesel to natural gas for power generation has started to reap immense benefits. Thus, the company is working hard to have its cement manufacturing plant begin production as well as reducing the cost of doing business at the sea port.

Aliko Dangote (Group) grew and acquired his business skills under another great entrepreneur known as Sanusi Dantata. In 1977, Dantata set Dangote on the path to entrepreneurial greatness when he gave him the seed money to begin trading in commodities and building materials. Subsequently, in 1981, Dangote had become so successful that he incorporated two other companies. And by 1997 (after calling his business teeth) he shifted his attention to the real sector manufacturing. And today, the group manufactures textile, cement, flour and agro-sac. Perhaps, Dangote has more than any other entrepreneur, impacted heavily on the Nigerian people and economy. In fact, he has the biggest wholly indigenous conglomerate (in terms of job creation and turnover) in the country as at today. Clearly, Dangote Group has fifteen manufacturing and bagging plants spread all over the country; and the plants run on the same of the best and latest technologies in the world. With government patronage or not, it indeed requires skills to grow and successfully manage such a vast business empire with an average annual return in the region of N40 billion. Equally to the Dangote's credit, is his ability to attract foreign capital into the productive sector of the economy. Specifically, of the $\$ 800$ million needed for his Obajama Cement project, $\$ 400$ million was committed by the International Finance Corporation (IFC), World Bank, Danish export Guarantee, FMO and European Investment bank. Indeed, according to the recent report from the forbes annual world's billionaires ranking, the Aliko Dangote's fortune surged 557 percent in the past year from 436 positions to 51 in 2011, making him the world's biggest gainer in percentage terms and Africa's richest individual for the first time. With presence in fourteen African countries, Dangote has emerged the continent's biggest cement maker, contributing significantly to other economies on the continent. In fact, Dangote is now richer than long time white South African billionaires. For now, he is gearing up to introduce Dangote cement to foreign investors. Thus, by this report, Dangote is now the richest black man in the world.

Nigerian Science Parks Clusters and Economic Zones

Nigeria is proposing the African largest science and technology park (to be known as the AFRICAN PREMIERINNOVATION CORRIDOR) along Abuja International Airport Road. Here the stakeholders include National Office for technology Acquisition and promotion (NOTAP), Abuja Geographic Information Systems, National Space Research and Development Agency, National Biotechnology Development Agency, African University of Science and Technology; Abuja Technology Village Complex; National Cancer center; Nigerian Communication Satellite Ltd and national Defence College, etc. NOTAP as an agency of Federal Ministry of Science and Technology is the coordinating agency responsible for the transfer agreements or contracts entered into by Nigerian entrepreneurs as well as conducting linkages between and among research institutions, industry, venture capitalists and financial institution. Again, the Raw material Research and Development Council (RMRDC) had already started the process of technologically developing business clusters in Nigeria. Table 3.1 shows the various economic zones. 
Table 3.1. NIgerian free (economic) zone

\begin{tabular}{|c|c|c|c|c|}
\hline $\mathbf{S} / \mathbf{N}$ & Name & Location & Status & Ownership \\
\hline 1. & Calabar Free Trade Zone (CFT2) & Cross River State & Operational & Fed. Govt. \\
\hline 2. & Kano Free Trade Zone (KFT2) & Kano State & Operational & Fed. Govt. \\
\hline 3. & Onne Oil and Gas Free Zone & River State & Operational & Private \\
\hline 5. & Tinapa Free Zone and Tourism Resort & Cross River & Under Construction & Private Public \\
\hline 6. & Olokola Free Zone & Ondo Ogun & Under Construction & State/ Private \\
\hline 7. & Maigatari border free Zone & Jigawa State & Operational & State \\
\hline 9. & Ladol Logistic Free Zone & Lagos & Operational & Private \\
\hline 10. & Ibom Science and Tech Park Free Zone & Akwa Ibom & Under Construction & Public Private \\
\hline 11. & Living Spring Free Zone & Osun State & Under Construction & State \\
\hline 12. & Airline services Export Prod. Zone & Lagos State & Operational & Private \\
\hline 13. & Lekki Free Zone & Lagos State & Under Construction & State/Private \\
\hline 14. & Egbeda Free Zone & Oyo state & Declaration & State \\
\hline 15. & OILSS Logistics Free Zone & Lagos & Declaration & State \\
\hline 16. & Brass LNG Free Zone & Bayelsa & Under Construction & Public Private \\
\hline 18. & Specialized Railway Industrial FTZ Kajola & Ogun State & Under Construction & Public Private \\
\hline 19. & Imo Guondong FTZ & Imo State & Under Construction & Public Private \\
\hline 20. & ALSCON FP 2 & Akwa Ibom & Operational & Private \\
\hline 21. & Ogun Guongdong Free Trade Zone & Ogun State & Operational & Public Private \\
\hline 22. & Sebore Farms & Adamawa State & Operational & Federal Govt. \\
\hline 23. & Calabar Freeport & Cross River & Operational & Federal Govt. \\
\hline
\end{tabular}

It is important to note that the Nigerian Chamber of Commerce, Industry, Mines, and Agriculture provide a useful umbrella for the search of generalized business information on Nigeria and global world.

\subsection{African Science Parks (Zones)}

Operationally, PRETOR/A (South Africa hosts the first science park on the Africa Continent (as at 2005). However, China's special economic zones in Africa include chambishi (Zambia), Lusaka (Zambia), Jinfei (Mauritius), Oriental (Ethiopia) and Suez (Egypt).

a. CHAMBISHI (China) Zambia - specializes in the production and processing of copper and copper related industries.

b. LUSAKA (China) Zambia - specializes in the production of garments, food, appliances, tobacco and electronics.

c. JINFEI (China) Mauritius - specializes in the production of manufactured goods (textiles, garments, machinery, high tech) trade, tourism and finance.

d. ORIENTAL (China) Ethiopia - specializes in the production of electrical machinery construction materials, steel and metallurgy.

e. SUEZ (China) Egypt - specializes in the petroleum equipment, electrical appliance, textile and automobile manufacturing.

Again, the SFAX SCIENCE PARK (TECHNOPOLE DE SFAX) was set up in TUNISIA in 2006 to promote computerization and multimedia. Here, a number of institutions and a research center specializing in computerization and multimedia, offer training and research activities in the park, which is creating muchneeded employment for the city's highly skilled but unemployed or underemployed workforce. In fact, SFAX is a major university center in the central part of the country with twenty institutions of higher education and 44,100 students enrolled in various subjects (science, technology, information technology, arts and engineering). Indeed, the science park has been designed as an integral part of the Greater SFAX Development Strategy, which maps out the city's integrated development to 2016. Yet, this science park is only one of the economic development tools leveraged to its development (http://www.investinTunisia.com).

Unfortunately, in sub-Saharan Africa, because the productive capacity of many clusters is suboptimal, they remain locked into low-quality, low income markets. Therefore, one way to build a cluster's productive capacity is to have it fully engaged in producing for demanding consumers. Although entering the export market would achieve that goal, very few are ready to make the leap because of production scales and capital and metrology, standardization, testing and quality assurance issues, among others. Yet, encouraging clusters to produce for demanding, high-volume local customers such as supermarkets, hospitals, and schools can enhance productive capacity.

\subsection{Foreign Science Parks (Zones)}

Zhongguancun (located in Beijing) China comprises seven separate science parks with about 17,000 firms. Operationally, Beijing boasts a very high concentration of skills: 37 percent of the members of the Chinese Academy of Science and the Chinese Academy of Engineering, twothirds of the country's PHDs and a pool of young graduates from some of the best universities in their country (39 universities and 213 research institutes as of December 2006) Thus, Beijing is undeniably a knowledge city in China. Similarly, TEKEL is an umbrella organization for 
finish science parks. It acts as an expert in and promoter of science park activities (as a national co-ordinator of network-based cooperation) and as a facilitator, creating and maintaining connections with the public sector, the business community, the education and research sectors and international networks in the field. In fact, the operational impact of TEKEL extends to 14,400 companies, 2,400 of which are based in science parks (http://www.tekel.fi) Again, in the Neapolitan economy, the informal economy represents a very high share of total economic activity and is plagued by organized crime and localized poverty traps. However, in 1999, the municipality and the University of Naples Federico II setup the urban operational centers for economic renewal (CUORE) to develop co-operation between the state and informal enterprises. Essentially, the project consists of a network of neighborhood service centers for entrepreneurs. Here, a team of specially trained young professionals are in-charge of identifying in formal firms and helping those willing to change their status. Basically, they offer them interesting incentives including marketing support (such as trade fair participation), cooperation with other firms as well as legal assistance.

\subsection{Modern Global Innovations (Inventions)}

Indeed, one of the chief ways in which intelligence presses forward is through innovation; which is now generally recognized as one of the most important contributors to economic growth. On the other hand, innovation depends on the creative individuals who dream up new ideas and turn them into reality. Practically, innovations can observed in any of the following fields: bioscience, computing and telecommunications, energy and the environment, social and economic innovation, business process innovation, consumer products, a flexible "no boundaries" category and corporate use of innovation.

1. Bioscience: Harald Zur hausen of the German Cancer Research Centre in Heidelberg demonstrated that human papilloma viruses (HPV) cause cervical cancer. His work led to the development of vaccines that now protect tens of millions of young women.

2. Business process: Peter Thiel and Max Lerchin, cofounders of the firm that went on to become Paypal that promoted the aid spread adoption of secure online payments. Essentially, this helped catalyze a wider embrace of online commerce.

3. Computing and telecommunications: John Cioffi pioneered work in the development of asymmetric digital subscriber line (ADSL) technology (which is the most widespread form of fixed broadband).

4. Energy and environment: Michael Biddle of MBA polymers developed mixed plastics recycling technology; which means that material that might otherwise end up in Landfill can be more easily recycled.

5. Technologies: TOSHIBA (PORTEGER700): This is another ground breaking stroke of genius from Toshiba. It offers exceptional performance in the shape of sophisticated innovation. As truly state of the art, it is one of the world's thinnest and lightest fully featured laptops inscribed with advanced technology to deliver best - in - class computing. In fact, one can experience artistic innovation with portege R700 that has everything needed for work and home: Intel core 17 Processor, Genuine Windows 7 professional, 13'3' Toshiba HD TF Display with LED backlight, mobile Broadband WWAN/3G, HDD protection and 3D Accelerometer, Spill - Resistant Keyboard, optical Drive Autolock, Fingerprint Reader, advanced airflow cooling technology with full processing power, and durable magnesium chassis with resistive honeycomb structure.

6. Neonurture incubator: The genius of the Neo Nurture incubator (developed by University Students in United States) is that it employs an under utilized resource (old car parts) to address a critical need; functioning in incubators to nurture premature newborns.

7. Antro electric car: This is indeed a car of the future that is coming from Hungary. Truly, the Hungarian a designer Antro might just have made a super efficient, super cheap car that could put western manufacturer to shame. Operationally, the Antro Solo can hold up to three people (a driver and two passengers) who pedal to help drive the ultra light car. And the rest of the forward motion comes from an electric motor that is partly by solar panels.

8. Electric car charging stations: Indeed, until a series of stations where drivers can charge their batteries, an electric car is in herently limited. However, Coulomb Technologies is working to break that deadlock. Consequently, the company is building a system of automated charging stations in public places that are connected to utilities so that the charge for your charge can be added to your home electricity bill.

9. Terrafugia transition (flying cars): The Terrafugia Transition and redefine the convertible and door to door travel. Designed by a team of MIT aeronautics engineers and terrafugia; the transition is a street legal (airworthy) airbag and parachute equipped flying car that is priced about $\$ 200,000$. By extending the vehicle's gull wings (as required to do so only at an airport) the rear - propeller powered transition can fly two passengers about $800 \mathrm{~km}$ at a cruising speed of $169 \mathrm{~km} / \mathrm{h}$. however, after landing you will be heading to the rental counter. Yet, the plane needs a mere $520 \mathrm{~m}$ of runaway to achieve liftoff. It is equally recommended that pilots open the gull wings only at airport.

10. Malaria - proof mosquito and mosquito laser: Unfortunately, the world's most annoying insect is responsible for 250 million cases of malaria per year as well as one million deaths. But scientists at the University of Arizona have genetically engineered a mosquito that is immuned to the plasmodium parasite immune (malaria causing agent it transmits with its 
bite). Subsequently, they intend to make the new mosquito harder than the ordinary kind and then release it into the wild; where it will displace the deadly variety. However, some inventors are currently developing a laser that can zap mosquitoes without harming other insects or humans. Operationally, the laser targets the mosquito's size and signature wing beat and sends the bugs down in a burst of flame making their deaths good for public health.

\section{Innovation Policy Strategies}

Innovation policy necessarily act within an established institutional setting; a setting already crowded with other organizations that consider themselves as legitimate actors in policy fields directly related to innovation. Therefore key innovation policy instruments often act as rudders, that is, they operate with limited financial resources but re-orient boarder masses of resources through clever incentives or influence the behavior of established institutions. Here, typical financial instruments for such purposes are matching funds, provided according to well-established criteria to key actors that mobilize their own resources. However, such mechanisms may give businesses matching funds on the condition that they invest an equivalent amount in a research and development project developed in collaboration with University or public laboratories. Yet, a second instrument is aimed at stimulating changes in the perspective and behavior of established communities and institutions and requires few resources. Such instruments include awareness rising through fairs or media campaigns; legal intervention and control (such as audits of institutions or overcoming obstacles to innovation).

Thus, for each nation, very specific behavioral features regulate the economy and society that have all sorts of implications for other aspects of life; business management, education, and training and government - citizen relationships among others. Therefore, in the African world, understanding these unique features determines the success of technology transfer and the adoption of modern management methods. Here, cultural characteristics present both strengths and weaknesses, and the policy implications are clear; build on natural strengths while being conscious of the weaknesses. Consequently, innovation policies in African countries should take into account of their specific features. Here, several points need to be emphasized: technology strategy, institutional issues, legal framework, countries' specific needs and assets, agents of changes, reforms and cultural and behavioral characteristics.

Indeed, the forces in a knowledge - based economy clearly indicate the need for a certain set of generic skills across industries, economies and regions. In other words, the ability to innovate will increasingly require individuals to be able to understand the nature of problems and to have the aptitude and creativity to address them. Thus, agents are now expected to move quickly between areas of expertise and to acquire new skills to keep pace with rapidly changing knowledge. Therefore, the tips of the technology development and innovation process include Research and Development ( $\mathrm{R} \& \mathrm{D}$ ) activities as well as non $\mathrm{R} \& \mathrm{D}$ activities; as the skills for acquiring, using and operating technologies at rising levels of complexity, productivity and quality. Similarly, the design, engineering and associated managerial capabilities for acquiring technologies develops a continuous stream of improvement and generates innovations. And because skills and knowledge can become quickly outdated, a person's capacity and potential are valued over his or her academic specialization and qualifications. Furthermore, the rapidly advancing knowledge frontier warrants a stronger emphasis on generic skills that provide the basis for adaptability and continuous learning. Essentially, what is arguably needed are competencies that go beyond knowledge and skills to include psychosocial elements such as values, attitudes, and the ability to apply skills in a particular context: cognitive, academic and technical skills, problem solving, creativity, social and interpersonal skills, work ethic, continuous and independent learning and premium on innovation management skills. Clearly, the economic advantage in a knowledge economy comes from the capacity to innovate by producing marketable goods needed to nurture this capacity which have to be seen in the context of the innovation process. While innovation involves the introduction and sale of new or improved products (PRODUCT INNOVATION) and the introduction and use of new methods of production (PROCESS INNOVATION), it also includes economic and social dimensions and activities that fall under the general heading of Business Innovation:

(a) Introducing new forms of business organization such as franchising, cooperatives, joint ventures, outsourcing agreements, and just - in - time manufacturing.

(b) Finding new uses and applications for existing products.

(c) Developing new markets for existing products and services and new sales and distribution channels (such as market differentiation) and internet based sale of goods and services.

Thus, different types of innovation may require different kinds of skills and competencies. Yet, through research on innovation, it is possible to highlight the skills needed in specific contexts. Again the notion of the product cycle helps show how the innovation process triggers changes in the demand for skills and how the evolving skills profile of the organization shapes the direction of subsequent innovation capacity. The results therefore indicate that a single qualification rarely provides all the skills needed for innovation in a person's working life.

Essentially, the spine of any educational system in the innovation - driven economy is the quality and reach of its primary and secondary education and the competence of its teachers. This is truly the basis of subsequent learning. Consequently, policymakers, educators, and citizens need 
to focus on the real goal of schooling to equip their nation's youth for full participation as adults in the economic, political and social activities of the knowledge economy. To this end, policy needs to promote up-to-date quality and higher standards in learning, teaching, and teacher education. Consequently, ways need to be found to adapt educational systems, meet the strong demand for secondary and higher education and deal with the fading frontier between general and vocational education. Unfortunately, the traditional educational systems in which the teacher is the sole source of knowledge are ill suited to equipping people to work and live in a knowledge ceremony. Here, competencies such as teamwork problem solving, and motivation for lifelong learning are not acquired in a learning setting in which teachers convey facts to learners whose main task, is to learn and repeat them. Therefore, providing people with the tools they need to function in a knowledge economy requires a new pedagogical model, which differs from the traditional one in many ways (as shown in table 4.1).

Table 4.1. Learning Models: Traditional Vs Lifelong

\begin{tabular}{lll}
\hline & Traditional Learning & Lifelong Learning \\
\hline a. & $\begin{array}{l}\text { The teacher is the source of } \\
\text { knowledge }\end{array}$ & $\begin{array}{l}\text { Educators are guide to sources } \\
\text { of knowledge }\end{array}$ \\
b. $\quad \begin{array}{l}\text { Learners receive knowledge } \\
\text { from the teacher }\end{array}$ & $\begin{array}{l}\text { People learn by doing } \\
\text { c. } \quad\end{array} \quad \begin{array}{l}\text { Learners work by themselves } \\
\text { eaple learn in groups and from } \\
\text { each other }\end{array}$ \\
d. $\quad \begin{array}{l}\text { Tests are given to ensure that } \\
\text { students have mastered a set of } \\
\text { skills and to ration access to }\end{array}$ & $\begin{array}{l}\text { Assessment is used to guide } \\
\text { learning strategies and identify } \\
\text { pathways for future learning. }\end{array}$ \\
e. $\quad \begin{array}{l}\text { All learners do the same thing. } \\
\text { f. }\end{array}$ & $\begin{array}{l}\text { Teachers receive initial } \\
\text { individualized learning plans. }\end{array}$ \\
& $\begin{array}{l}\text { training plus adhoc in-service } \\
\text { braining }\end{array}$ & $\begin{array}{l}\text { initial training and ongoing } \\
\text { professional development are } \\
\text { linked }\end{array}$ \\
g. & $\begin{array}{l}\text { Good learners are permitted to } \\
\text { continue their education }\end{array}$ & $\begin{array}{l}\text { People have access to learning } \\
\text { opportunities over lifetime. }\end{array}$ \\
\hline
\end{tabular}

In other words, a life long learning system must reach larger segments of the population and address diverse learning needs. Here, it must be competence driven rather than age related. Therefore, traditional institutional settings require new curriculum and new teaching methods. Similarly efforts need to be made to reach learners who cannot enroll in programs at traditional institutions. Beyond formal general education, vocational education and training play a crucial role, as well as other informal mechanisms by which youth and adults acquire needed skills.

Operationally, private entrepreneurs and productive enterprises are at the centre of self discovery process. Here, their risk taking and experimentation are supported by an innovation system: a network of organization, rules, and procedures that affect how a country acquires, creates, disseminates and uses knowledge. Here, key organizations participating in the private sector's self-discovery process are universities, public and private research centres and policy think tanks. Thus, for the innovation system to be effective the private sector must require knowledge; and effective links between research and development (R \& D) and industry are vital for transforming knowledge into wealth. Therefore, self - discovery is a collective process that takes place through networking and yet, interactions among the different organizations, firms, and individuals are critically important. Obviously, institutions in African countries may be dysfunctional but they are not uniformly so. In fact, within a given ministry, some segments or individuals perform better than others and these can be beverage to transform a difficult institutional environment. Therefore, search networks are networks of individual and institutions that solve complex problems by finding individuals who already are working on the solution to (part of) the problems. Consequently, strategic pilots make it possible to institutionalize emerging search networks to bring together champions from private and public sectors and (possibly) the country's talent abroad. In other words, search networks encourage change and reform by linking together the better performing segments of national economies. However, double transformation involves the creation of an appropriate context for reform. Clearly, reforms that start from the better - performing and more entrepreneurial segments of the economy are more likely to succeed.

Thus, the demonstration effect makes the diffusion of reform to other segments of the economy easier; and it also neutralizes the resistance of rested interests. Definitely, the introduction of new pilots means cutting down an existing programs; not only to provide budget space to trigger piloting and experimentation but to provide the correct incentives for players to perform. In other words, under performing projects are sealed down and released resources are relocated to test new trapping.

Finally, the bootstrapping approach involves a bold vision and strategic change in the long run though a gradual of incremental bottom-up changes in which a favorable balance of risks and returns encourages initial steps at many entry points. In this process, each more increases the chances of initiating a virtuous cycle of institutional reforms and private sector development. Therefore, policy - makers considering bootstrapping need to be prepared for the emergence of unexpected coalitions for reform. Generally, the prevailing view of reform starts with the design of blue-print for change (that is a blueprint with a known outcome). However, to detect problems and errors, policy makers should constantly monitor and benchmark the process of reform and restructuring.

\section{Conclusion}

Basically, innovators are entrepreneurs and they need marketing intelligence and basic support as the product or process they seek to introduce is new. Innovations (in the form of new products and processes) are therefore introduced in the market - place because of these dynamic 
entrepreneurs. Essentially, they require market - relevant investment in research and development (R \& D), creativity, and often cooperation with institutions of higher education and firms. Because the outcomes of innovation are highly uncertain; firms and entrepreneurs are often reluctant to invest sufficiently in $\mathrm{R} \& \mathrm{D}$, and risk adverse behavior often stifles creativity. Furthermore, the lack of an enabling environment and the difficulty of appropriating the economic benefits of investment in innovation hamper the development of collaboration between firms and between firms and research institutions.

Therefore, governments are often called on to bridge the gap and address these issues. Practically, the generation (diffusion) of new technology (knowledge); government efforts to transfer technology; and the educational system's ability to produce science (engineering) graduates influence a country's innovation capability. Moreover, the absorptive capacity of firms is crucial for translating innovative ideas into productive gains. Again, the proximity of firms to each other helps bind these various dimensions into an innovation system. As a result, support for innovators is often the result of initiatives by local or regional governments, which have more knowledge and better information would local firms with high potential and can better access the risks linked with local or regional innovation than the national government. Consequently, central and sub central governments have a range of business assistance programs to support innovators:

(I) Sector-oriented entities and technology transfer centres serving mainly new and small enterprises.

(II) National or regional small business policies that seek to meet the needs of firms at various stages of the innovation process (design, development, diffusion).

(III) Access to equity and (venture) capital to help develop new products and processes and to mitigate the risks of commercialization.

(IV) Government support of clusters and networks as they became major actors in innovation.

(V) New policy approaches to intermediaries and bridging institutions.

Operationally, the business incubator is the instrument must widely used to support these various initiatives. To nurture the development of firms, business incubators offer, on a temporary basis, and at relatively low cost, the use of shared premises, capital equipment, and business and technological services. Clearly, incubators have diverse sponsors and stakeholders, including government agencies universities, chamber of commerce and non profit organizations. Similarly, Private for profit agents also sponsors business incubators as part of business estate venture. Thus, the convergence of innovation and enterprise policy and business estate initiatives is an area over which local authorities have significant control. However, incubators increasingly tend to specialize so that they can provide tailored responses to a wide variety of small innovative firms (gazettes). In other words, these are small firms in specific sectors or clusters, microenterprises in need of mentoring and small firms with a narrow customer base (among others). And yet, beyond access to R \& D and physical facilities (incubation); commercialization of technology requires access to adequate capital for dealing with the uncertainties of the innovation process and providing a robust financial base. In fact, early development of new products and processes generates little and often no profit. Therefore, bridging the financing gap is crucial for new firms or for autonomous development of innovation projects.

Consequently, finance for innovation usually comes from internal sources (cash flow), but when substantial investment is required, external investment maybe needed. Yet, outside investors may not have confidence in entrepreneur's ability to manage risky ventures or they may find it difficult to identify good projects. Consequently, this myopia in the innovation market warrants government intervention and the use of public money to provide grants and incentives to innovating firms and entrepreneurs. Unfortunately, a key constraint to the successful commercialization of research outcomes is the lack of early stage investment capital. To reduce these constraints and induce venture capitalists to finance projects that transform the research outputs from universities or public labs into ammenial success; recommend improved stock market regulations and intensified support for venture capital by allocating larger budgets to venture capital, especially for SMEs and technology - based start-ups by providing tax incentives to non resident investors and by forming partnerships with private ventures capitalists. Furthermore, there are various schemes for new firms and SMEs, including general guarantee schemes, matching of investments made by small business investment companies with public loans, seed capital schemes or schemes that enhance equity. Again, angel investment is an important source of informal equity capital and angel investors often provide critical know-how as well as capital.

As a last remark and for social equity, a pro-poor innovation system can be defined as a multi stakeholder social learning process that generates new knowledge (puts it to use) and expands the capabilities and opportunities of the poor. That is, in pro-poor innovation processes, institutions play a critical role; they determine extent to which the poor are able to participate in the innovation process and share in the potential benefits. Here, institutions include social norms of behavior, habits, routines, values and aspirations, as well as laws and regulations (all of which are rooted in a given society's history and culture). However, governments can facilitate the expansion of financial services to the poor by establishing a friendly regulatory framework and by providing banks with technical assistance on lending to the poor. Thus, partnering with donors in this regard may be useful as a number of development agencies can establish training programs for banks on pro-poor financial products and are experienced in providing partial credit guarantees to encourage banks to lend to this segment. It is equally 
important to consider the need for finance when developing skills building programmes for the informal sector. Here, training programs will be much effective if they are linked with loans to enable the creation or expansion of businesses based on the new skills. Therefore, government agencies, NGOs donors and private corporations organizing training for their suppliers should attempt to establish partnership programmes with the banks at the inception of such initiatives.

Unfortunately, a number of organizations (national and international research institutions, informal and formal enterprises, various ministries, NGOs and private companies) have unrealized synergies. Thus, governments in African countries should aim to foster links among such actors both to facilitate creation and commercialization of pro-poor innovations and to ensure effective knowledge transfer to the poor. In addition to establishing a business friendly regulatory framework, governments can support collaboration among these actors by improving access to information on the needs of the poor and on the technologies available to address them; allocating a percentage of the national budget to support collective propoor R \& D efforts by different organizations, and developing sectoral programs on knowledge transfer to the poor.

JEL NO: D20, L60, L70, L26, L90, M13, 030, 031, 032, Q10, Q20, Q30, Q40, R10, Q50

\section{References}

[1] Africa Development Bank (2007) Report of the High level Panel: Investing in Africa's future, Abidjan: African Development Bank.

[2] Nwaobi, G. C. (2000) The Knowledge Economics: Trends and Perspectives, Lagos: Goan Communication press.

[3] OECD (2008) Science, technology and industry outlook, Paris: OECD.

[4] Oyelaran - Oyeyinka, B. (2006) Learning to Complete in African Industry:

[5] Institutions and Technology, Development, Hampshire: Ashgate publishing.

[6] UNIDO (2002) Industrial Report, Vienna: UNIDO

[7] United Nations (2007) The Millennium Development Goals Reports, New York: United Nations

[8] World Bank (2009) World Development Report (Reshaping Economic Geography),

[9] Washington: World Bank.

[10] World Bank (2010) Innovation Policy, Washington: World Bank.

[11] Zeng, D. (2008) Knowledge Technology, and Cluster-based Growth in Africa, Washington: World Bank. 